\title{
Students' Lack of Interest: How to Motivate Them?
}

\author{
Yesmambetova Kazina Nagashibaevna \\ School-Lyceum № 3, Zhankozha Batyr St, 5, Kyzylorda, Kazakhstan
}

Copyright@2019 by authors, all rights reserved. Authors agree that this article remains permanently open access under the terms of the Creative Commons Attribution License 4.0 International License

\begin{abstract}
Passive learners usually do not have the kind of instrumental motivation and determination for learning English. A sample dictionary definition of passive is "accepting or allowing what happens or what others do, without active response or resistance". Passive learners take in new information and knowledge quietly, but they typically do not engage with the information they get. This behavior can negatively impact learning experience. Passive learners find themselves very uncomfortable when they are forced into a self-paced - and active learning. Therefore, English lessons must be fun and rewarding. Teachers should engage the passive learners to group work or other strategies to cultivate students' critical thinking skills. Highly visual aids with interactive lessons that rely less on written text will provide accessible support for such learners to become critical thinkers. Critical thinking includes the component skills of analyzing arguments, making inferences using inductive or deductive reasoning. It involves both cognitive skills and dispositions. Teachers are urged to provide explicit instruction in critical thinking, to teach how to transfer to new contexts, and to use collaborative learning methods and constructivist approaches that place students at the center of the learning process.
\end{abstract}

Keywords Passive Learners, Critical Thinkers, Collaborative Learning

\section{Introduction}

My article is about the ways to interest the passive learners into the lesson and its effectiveness. There will be described different ways of the motivation for students with less interest. The activities will help teachers encourage all students to be proud of their own achievements. It is true that most students wish to please the teacher, so it is the job of the teacher to encourage all students to be proud of their own achievements and to raise their self-esteem. So, the student continues to give maximum effort and increases personal success.

Teachers should engage them to group work or other strategies to cultivate students' critical thinking skills. Some children are highly motivated and the others are highly competitive and enjoy gaining greater success than their classmates.

Teaching is one of the greatest ways to develop students' linguistic skills that they can more effectively communicate. Furthermore, nowadays teaching is getting hard because of new generation. They want to know more and more and it makes you work harder and find other new ways of teaching. It is very important for the teacher to organize different out of class activities to improve students' speaking skills and to make learning English joyful and more interesting. Here I would like to illustrate some characteristics for the teacher to have a good lesson. A good teacher should:

1. respect his/her students;

2. come to class prepared, and with a solid direction;

3. be a team player with students;

4. be creative and can present the same idea in many different ways;

5. fair with all students and treat all students equally;

6. be available to his/her students, not aloof;

7. make learning fun and clearly has fun as well;

8. passionate about teaching and it clearly shows;

9. be enthusiastic about being in the classroom and have a positive attitude;

10. be patient, not all students are perfect, but most truly want to succeed.

It is true that sometimes we have some problems with our students. What problems do we have with them?

- not controlling the students in the classroom

- not knowing how to motivate them at the lesson

- $\quad$ lack of professionalism

\subsection{How Should We Solve These Problems?}

\subsubsection{Lack of Classroom Management}

If a teacher cannot control the students in their classroom they will not be able to teach them effectively. Being a good classroom manager starts on the first day one by incorporating simple procedures and expectations and then following through on predetermined consequences when 
those procedures and expectations are compromised. Any teacher trying to be friends with students will be ineffective in the area of classroom management. Students will test teachers quickly, recognize a weakness, and take over a class before a teacher knows what happens.

\subsubsection{Lack of Motivation}

There are some teachers who do not challenge their students, rarely give homework, are often behind on grading, and give "free" days on a regular basis.

There is no creativity in their teaching, they rarely smile or seem excited to be there, and they typically make no connections with other faculty or staff members.

\subsubsection{Lack of Professionalism}

Professionalism encompasses many different areas of teaching. A lack of professionalism can quickly result in a teacher's dismissal. Teachers who are routinely absent or tardy are ineffective. They cannot do their job if they are not there to do it. Teachers who use inappropriate language in their classroom on a regular basis undermine the moral responsibility they have as an authority figure. Each of these situations involves a serious lack of professionalism which will undermine a teacher's overall effectiveness.

It is clear when you prepare your lesson; you start by planning the main components you want to include, for example a grammar exercise, or the reading of a text. But once you have prepared the main components of your lesson, and made sure it is varied and interesting, you may find that you still need some extra ingredients to make it smooth, and integrated unit. So you may need:

- a quick warm-up for the beginning to get your students into the right mood for learning;

- $\quad$ an idea for a brief vocabulary review before starting a new text;

- a brief orientation activity to prepare a change of mood or topic;

- a game or amusing item to round off the lesson with a smile.

Apart from this it is important that children should recognize that making mistakes is part of the learning process and by developing strategies to rectify their mistakes they will be able to solve them in future. I think it is the teacher who can control and know his/her students better. Taking into consideration that they are from different families and have different attitude to school it is vital that the teacher is sensitive to the needs of pupils. In fact, they are individuals, so it is important for the teachers to differentiate between the success of the individual and comparisons with other children of the same age. If the teacher can find the way to the heart of the student students can trust him/her.

I think one of the ways to making students think and work with great enthusiasm is critical thinking.

Critical thinking is a disciplined approach to conceptualizing, evaluating, analyzing and synthesizing information from observation, experience, reflection

or reasoning. [1] It is often associated with a willingness

to imagine or remain open to consider alternative perspectives, to integrate new or revised perspectives into our ways of thinking and acting, and with a commitment to participatory democracy and fostering criticality in others.

The skills involved in critical thinking include the ability to:

- recognize problems, to find workable means for meeting those problems;

- $\quad$ gather relevant information;

- recognize unstated assumptions and values;

- comprehend and use language with accuracy, clarity, and discernment;

- interpret data, to appraise evidence and evaluate arguments;

- $\quad$ recognize the existence (or non-existence) of logical relationships between propositions;

- draw warranted conclusions and generalizations. [2]

I think it is the question for all teachers in how to interest their students in the lessons. To my way of thinking, the answer is to use critical thinking activities as it helps the students to be involved in lessons. At my lesson I try to use different activities which encourage my students. These activities help them think, imagine and work creatively. Now I would like to describe some of them.

If we remember Bloom's taxonomy Evaluating is the second-most complex activity, and Creating is at the top. It means we should pay more attention to students' creativity and analyzing [3].

Before we can understand a concept we have to remember it

Before we can apply the concept we must understand it

Before we analyze it we must be able to apply it

Before we can evaluate its impact we must have analyzed it

Before we can create we must have remembered, understood, applied, analyzed, and evaluated.

Thinking in terms of skills what we want our students to be able to do is a more effective way of communicating because doing so helps us reveal the complex processes inherent in what we require. As a teacher how do we know our students learned the concept? Typically, this is through observable behaviors, using the knowledge to accomplish a task.

\section{Activities}

Selecting and designing tasks involves not only a sound understanding of the material to be taught, but also matching the level of work to that of the students. So you should:

- provide opportunities for students to reflect on and share their personal experiences and their feelings about the topic being studied; 
- draw on what students already know and can do to stimulate their interest and imagination;

- $\quad$ select tasks that are challenging and achievable.

\section{Controversial Statements}

Procedure: Write up two or three controversial statements, or proverbs, on the board. Each student writes down 'agree' or 'disagree' or 'don't know' for each item. Invite them to compare their answers in pairs or threes. Then find out what the majority opinion on each is, by vote. If you have time, discuss them.

\section{BOX: Controversial statements \\ 1. Beauty is only a matter of taste. \\ 2. Riches are for spending. \\ 3. Punishment never does any good. \\ 4. A woman's place is in the home. \\ 5. People work better if they are paid more. \\ 6. Everyone is basically selfish. \\ 7. A foreign language can only be leamed, not taught.}

\section{Correcting Mistakes}

\subsection{Procedure:}

Write up a few sentences on the board and deliberate mistakes in them. If you wish, tell the students in advance how many mistakes there are in each sentence. With their help correct them. [4]

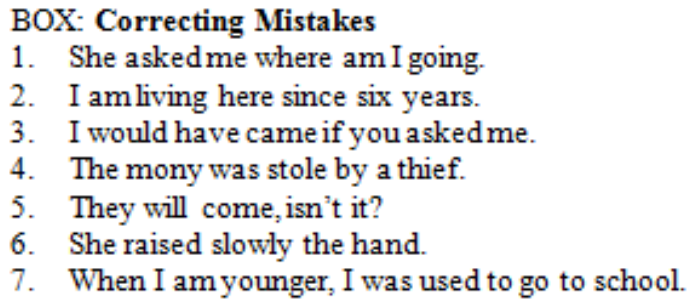

Learners may be motivated to participate in a learning exercise by extrinsic factors that have nothing to do with the nature of the activity itself - they may very much need to know the language, for example, or want to be approved of. But here we should be concerned with intrinsic motivation: what kinds of features within the activity itself arouse learners' interest and make them want to take part in it?

\section{a) Topic}

The content of the activity is obviously a major factor in arousing - learners' interest. The importance of the topic as a focus varies: if the activity is a discussion or essay on a controversial subject. But if the activity is a game-like one where the emphasis is on problem-solving then the subject matter becomes relatively unimportant, and the task itself is what provides the interest.

There is no single 'recipe' for the selection of subjects that will arouse learners' interest, but it may help to ask yourself the following questions: Is my topic something that my students can relate to because they know something about it and it arouses definite positive or negative reactions? Or alternatively, something they would like to find out more about, and can do through participating in the task?

\section{b) Visual focus}

It is very much easier to concentrate on thinking about something if you can see that something, or at least see some depicted or symbolic representation of it. Learners (particularly younger ones) who are asked to discuss or listen to something without any visual focus often find their attention wandering. This is because sight is an extremely powerful and demanding sense: if you do not provide your students with something to look at, they will seek and find it elsewhere. An exercise that uses both aural and visual cues powerful and demanding sense is likely, therefore, to be more interesting than one that is only speech-based.

\section{c) Information gaps}

It is true that the transmission of new ideas from one participant to another does occur in most real-life language-based transactions, and when this factor is built into a classroom language learning task, the effect is to add a feeling or purpose, challenge and authenticity which improve learner interest. For example, learners are often asked to practice the interrogative by taking an answer and reconstructing the question; a useful exercise for sharpening awareness of interrogative forms, but certainly not outstandingly interesting. If, however, students interrogate each other in order to get the necessary information to fill out a form, then they are asking questions whose answers they do not know in advance, but need in order to perform a task, and their interest in both question and answer is likely to be much greater.

\section{d) Entertainment}

Another source of interest is sheer entertainment: the reception or creation of ideas or graphic forms that are in some way aesthetically pleasing or amusing, or both. Listening to stories or songs or watching films or plays can obviously give pleasure. Exercises that are based on combining or comparing ideas not usually juxtaposed can produce all sorts of amusing results: 1.1 Desert island equipment, for example, where participants have to find reasons to justify using unexpected articles on a desert island. Apparently straightforward brainstorming procedures often produce entertaining contributions: how many things can you think of that you might/could do with a pen, for example, 1.2 Uses of an object: students get pleasure from both composing and hearing (or reading) original ideas. 


\section{Desert Island Equipment}

Use of can/could/may/might to express possibilities, free composition of sentences based on situation and object cue.

Materials: A pile of small pictures of objects. You could use drawings or bits of magazine pictures, or published small pictures for language learning.

Procedure: Tell the students they are stranded on a desert island. They have a pile of items in front of them, each of which they may keep if they can find a convincing use for it in the desert island situation. In turn, each student picks up a picture, and suggests how he/she can/could/may/might use whatever it depicts. For example, a student who picks up a picture of a shirt might suggest: We could use the shirt as a flag to signal to ships

Variations: The activity may be presented as an inter-student or inter-group competition. The challenge of finding uses is often motivating enough in itself, and groups can be asked at the end to share their most original ideas, or tell the class what they can do, in general, on their island as a result of having all this equipment.

\section{Uses of an Object}

Use of can/could to describe possibilities, oral brainstorming.

Materials: A picture of a simple object, or the object itself.

Procedure: Invite the students to suggest as many original uses for the object as they can use can/could. For example, if the object is a pen, students might suggest:

You can use it to dig holes.

You could scratch your head with it.

After initial demonstration with the full class, divide the students into groups, and give each group an object. They have three or four minutes to think up all the uses they can, noted by a 'secretary'. Help them with new vocabulary as necessary. Later, the groups' report back with their suggestions which are usually entertaining enough in themselves to provide interest, or the activity can be made into a competition between groups to see who can produce the most ideas. [5]

Guess my story

Level

Lower-intermediate

Materials

Time

2 lessons of 40 minutes each

Focus

Listening; asking questions; note-taking; oral summarizing; writing
For this activity you need to have two stories in mind, each of which you could tell your class. But you end up telling only one!

\section{Procedure}

\subsection{First Lesson}

1. Tell your learners that you have prepared two stories for this lesson and that you are going to tell them only one of two.

2. Tell them that they have to decide which of the two stories they want to hear, story A or B. Add that first they need to find out a little about each of the two stories so that it will be easier for them to decide which of the two stories they want to hear.

3. Tell the group to ask you lots of questions about each story. Do not give too much of the story away in your answers. Your answers should hook the group's interest in the story, but at the same time they should also be a little vague and fairly open.

For example:

S1: Is story A a fairy tale?

$\mathrm{T}$ : It's not a fairy tale, but there is an element of magic in it.

S2: Is there a magician in story A?

$\mathrm{T}$ : No, all the people in the story are quite ordinary people, apart from one person. She's a bit strange, you know.

1. After a while, ask your class to work in pairs. Each pair should summarise for themselves what they know about each of the two stories. Ask them to make notes.

2. Give them some more time to ask you further questions. Proceed as described in Step 3.

3. In pairs, learners decide which of the two stories they want to hear and why.

4. Get each pair to report their decision and their reasons to the whole class.

5. Tell the class the story the majority wanted to hear. Ask them to keep their notes for the next lesson.

\subsection{Second Lesson}

1. Get your class to work in the same pairs again. Ask them to look at their notes of the story that you have not told. In pairs, they write a story based on their notes.

2. Each pair reads their story out.

3. Tell the story. [6] 


\section{Desperate Decision (Problem-Solving Activity)}

\begin{tabular}{|ll|}
\hline Aims & Skills - reading comprehension, speaking \\
& Language- making suggestions, stating possibilities, agreeing and disagreeing \\
Level & Intermediate/advanced \\
Organisation & Groups of three to six students each \\
Preparation & A handout for each student \\
Time & 40 minutes \\
\hline
\end{tabular}

\section{Procedure}

Step 1: Each student receives a handout and reads the description of the situation. Comprehension difficulties are cleared up, and the teacher may ask a few comprehension questions (e.g. How many of the hiking group are feeling ill? How many can read a map?).

Step 2: The groups try and find as many causes of action as possible. They should write them down. Then they discuss advantages and disadvantages of each solution and decide on the best one. Again they should write down the reasons for their choice.

Step 3: Each group present its solution. The other groups should challenge the arguments and conclusions of the reporting group. [7]

Picture description. The students will be given a story "The Man in the Blue Car". Describing the pictures the group will make a story. Then they will listen to a true story.

When I use this activity my students usually give different answers and I think it is good, because they try to think about the event of the story. It is their own idea especially about the cat in the picture. Some of them think the cat might fall down from the balcony or another answer is it was running away from the dog

and appeared at the top of the car. At the end when they know the real story you can see happy faces or still thinking eyes about the story.

Any learning situation can be meaningful if learners have a meaningful set - that is, a disposition to relate the new learning task to what they already know, and the learning task itself is potentially meaningful to the learners - that is, relatable to the learners' structure of knowledge. [8] We can make things meaningful if necessary and if we are strongly motivated to do so.

How should we keep our students motivated?

I would like to give some tips I have collected over my working years:

Involve your students. If you do not involve your students in your lesson, you will not keep them motivated. Being as a facilitator and a coach, the teachers should help and direct the learning process.

Give students the chance to shine. It is also important to give students the opportunity to be successful. When you give them different tasks you can see the results of their efforts. You can also see shining faces that have done difficult tasks correctly. It is time for them to praise for their motivation.

Make your lesson fun. When I say 'fun', I mean that the students should be able to enjoy themselves and feel relaxed. I do not mean you have to play games and stuff every lesson, I think certain amount of games and playing reduces tension in the classroom. In my opinion, it is also very important that they go away feeling that they have done something right and, they have learnt and achieved something.

Give clear instructions. When setting a task, allow students time to prepare first and try to give clear instruction of each task. They need to have a very clear idea of what they are supposed to.

Talk to your students. The teacher should be able to talk to their students like a person instead of a child and they should be able to talk freely with the teachers about their school and any problems that they have. The school rules should be fair not strict and not lenient.

Group students. Breaking the class up in groups will contribute to class discussion and problem solving. Poll your students about their working preference, or experiment with breaking them up in different ways. Divide the students in half, place them in small teams of three or four, or divide them up in pairs. Working collaboratively even shy students can be involved in your lesson.

Taking everything into account, I would like to say that staying awake and interested in class can be difficult. But what is even more difficult is being responsible for keeping students awake and interested. This is the job of any ESL teacher first and foremost. In order to be a great ESL teacher, one must not only teach, but inspire and empower. As the quote says: "The best teachers teach from the heart, not from the book" or "A good teacher is like a candle - it consumes itself to light the way to others". The goal of teaching is to excite the students about learning, speaking, reading, writing and comprehending English. Keep the advice in this article as a tool to be used often, and you will be one step closer to that goal. 


\section{REFERENCES}

[1] Defining Critical Thinking. The Critical Thinking Community, available at: http://www.criticalthinking.org/pa ges/defining-critical-thinking/766.

[2] Handbook for teacher. Cambridge, 2012

[3] Bloom's Digital Taxonomy. Educational Origami, available at: http://edorigami.wikispaces.com/Bloom+Digital+Taxon omy.

[4] Five-Minute Activities. A resource book of short activities. Penny Ur \& Andrew Wright. Cambridge University Press, 1992

[5] Grammar Practice Activities. A practical guide for teachers. Penny Ur. Cambridge University Press, 1988

[6] The Standby Book. Activities for the language classroom. Edited by Seth Lindstromberg. Cambridge University Press, 1997

[7] Keep Talking. Communicative fluency activities for language teaching. Friederike Klippel. Cambridge University Press, 1999

[8] Principles of language learning and teaching. H.Douglas Brown. Pearson Education Company, 2000 